THE APPROACHING REVISION

oF

\section{THE BRITISH PHARMACOPEIA}

V1.

\section{'IHE CRI'TERIA FOR THE ADMISSION OF NEW REMEDIES.}

BY J. THEODORE CASH, M.D., F.R.S., Professor of Materia Medica. University of Aberdeen.

Impontant as the work of elimination from the old volume may be, much of the value of the coming edition of the British Pharmacopocia will depend upon the new remedies which find their way into it. As this extension forms an essential part of the Pharmacopœia Committee's plan, it may be advisable to consider the principles which should be borne in mind in the selection of such remedies.

The first and most important of these principles is embodied in the question, Is the knowledge of a certain remedy sufficiently favourable and precise to ensure its accurate and reliable employment in the treatment of disease? Stress has already been laid upon the advantage of having our list of remedies and their preparations no longer than is necessary to render the equipment of the practitioner as efficient as the existing state of our knowledge admits. But this limitation must go hand in hand with the recognition that only such bodies are added to the list as have an established and ascertained position. If the position is regarded as uncertain and resting upon slight or insufficiently tested evidence, by all means let the alleged remedy serve its probation outside the Pharmacopoia. This volume cannot anticipate to any large extent the future requirements of practice or the means of supplying them; its remedies may be in time superseded by others, its preparations of remedies may give place to better ones; all that is possible is to make use of the research and observation which is now available. But the fact that a remedy stands in the British Pharmacopcia should be a guarantee to the practitioner that it is of ascertained efficiency in an indicated sphere of action, whilst each and every form in which it is presented should be reliable and representative in its effect.

It will be asked from what sources is such a guarantee to be satisfied? The essential sources I believe to be therapeutical and pharmacological observations, but in many instances, according to the nature or the origin of the body, the work of the chemist, and frequently that of the botanist, must also be considered indispensable in character.

It is neither conducive to the accuracy of pharmacological research nor yet of treatment, that we should work with bodies whose constitution is not understood, and which may contain principles divergent or even antagonistic in their action. Neither is it advantageous when a new vegetable product is under consideration that any doubt should be left as to its precise botanical source. In other words, it is desirable to knnw exactly what we are dealing with, and whence its supply is to be drawn.

If medical science is to progress it must rest upon close observations of the action of remedies both in health and disease, and therefore the most important sources through which these can reach official recognition are pharmacology -under which term one department of experimental pathology must be considered as implied-and therapeutics. As a means of analysing action upon healthy organs and tissues, and thereby indicating the direction in which the new substance may be utilised in treatment, the former is essential ; but its results must have been satisfactorily translated into the successful treatment of human disorders, before the most important requirements for admission to the Pharmacopocia are to be regarded as satisfied.

Such sources only will furnish us with bodies which can be employed accurately, scientifically, and effectively, and will reduce the already slackening grasp of empiricism in practice. and thereby raise the standard of treatment to a higher and more worthy level.

But, again, contributions to our knowledge from such sources must be precise and discriminative if they are to serve in this important direction. To a much larger extent in some other countries than in our own it is the business of the enterprising vendor of new remedies to find a field for his products such as may bring them into the position of utility which he no doubt honestly believes they are entitled to occupy. He is desirous of the backing of the practitioner, and it is scarcely to be expected that he should weigh the merits of such written support as he receives before he utilises it in his enterprise. But the medical man who analsses the majority of such testimonials-one is almost tempted to call them "presentation bottle testimonials"-is apt to be struck with their worthlessness as evidences of careful employment or of close observation of the effect occasioned. "I have found it excellent in kidney troubles," runs such a testimonial. In what kidney troubles?-if, indeed, we admit a term which may imply a multitude of disotders, or of symptoms of disorders, calling for widely diverse methods of treatment. How was it given? What is the rationale of its action? These and many other questions will suggest themselves to the practitioner who desires to follow as accurate and intelligent a course in his treatment as is possible.

Such faulty and inexact therapeutical statements are worthless, they may be positively misleading. and it is not by them that a remedy will receive its justification. The difficulty must be recognised and acknowledged of introducing supposed remedies directly into the service of therapeutics, without a previous elucidation of their action by means of pharmacological research, which renders it possible for the practitioner to find an explanation for the bevefit that may accrue from their use. In a word, unless we have studied the manner of action, our employment of remedies is apt to degenerate into a more or less pronounced empiricism which goes no further than the assertion, "It does good, and therefore I use it." This is the chief origin of the inconclusive and valueless character of the support often accorded to a new remedy.

When the practitioner knows precisely what he is using, how it acts, and what are its potentialities for curative purposes, he goes to his work with a degree of confidence and of satisfaction which is otherwise denied him ; and by his careful and thoughtful adaptation of his knowledge he enriches and promotes the progress of medical science. These are therefore to be regarded as the chief desiderata which should recommend a new body for admission into the British Pharmacopoia.

but beyond the main consideration, others present themselves before the new body should be enrolled in the official list. Is there a distinct necessity for its inclusion in the Pharmacopocia? Is it more effective than similar remedies already represented there? Is it safer, or does it possess other conspicuous advantages? Is it a body which promises to cover a field of action hitherto entirely barren or imperfectly occupied by older remedies?

There are now existent a multitude of products, hypnotic and antipyretic in properties, largely supplied by the synthetical skill of the chemist, but it would be disadvantageous to introduce most, or even many of these, unless they can be shown to possess some of the advantages just touched upon.

If a hypnotic is to be found amongst them which acts steadily and equally in simple insomnia or conditions of excitement, which does 'not cause any after-disturbance, which is easily administered and easily taken, it will be such an ideal remedy of its class that it would be a manifest injustice to exclude it from official recognition. But it may be questioned whether such a hypnotic is as yet available. With reference to those which have much to recommend them, a very careful eye should be cast over the records of prolonged administration, as it is quite evident that some of them are by no means free from danger when so employed, and if they stand for recognition in contrast with bodies which do not possess such a drawback, the latter should, if their action is to be otherwise depended on, be preferred.

If the value of such a remedy is so great that it must be allowed admission, in spite of a disadvantageous effect of this character, much may be done by giving information as to the time- and dosage-limit of safe administration, in order 
to make its employment serviceable and free from anxiety to the practitioner. such questions might arise with regard to official sulphonal, and the related non-pharmacopœial compounds, trional and tetronal. If theobromine and its salts are shown to be as energetic diuretically as caffeine, and at the same time to act without occasioning the sleeplessness and excitement often following the latter, a distinct gain would result from their recognition.

As it is important that the Pharmacopoia should be as representative as possible in the directions in which its remedies act, special attention may well be drawn to those which are serviceable in disorders, the treatment of which is imperfectly or not at all provided for.

The first examples which suggest themselves are thyroid extract, antitoxins, and serums, regarding which our knowledge is increasing from day to day. These, I understand, will be specially considered in a later article of this series. Beyond this domain, however, let me refer to one or two bodies simply by way of illustration and not because I am prepared to support their claim for admission.

If all that has been claimed for piperazine could be substantiated we should have in it an agent which would do more as a litholytic than has been fairly claimed for any one pharmacopoial remedy.

If it was considered as satisfactorily proved that orexin stimulated the appetite far more energetically than bitter tonics hitherto in use, and did not provoke gastric disorder, it would be entitled to a place amongst valuable additions to our remedies, though it would be necessary to remit it to the pharmacist in order that by the resources of his art he might attempt its conversion into a palatable form.

Had bromide of ethyl been found to be not only more prompt in action, but less dangerous for short operations, than chloroform, it might not have been deemed unworthy of introduction, for there are at the present moment few fields of action less satisfactorily provided for in the official list than that of the general anæsthetist.

If jambul had justified the earlier notices of its action in the treatment of diabetes, what a welcome addition it would have been to the meagre and inefficient equipment we possess in this direction! Hypothetical examples might be brought forward in great numbers, but these given may serve to illustrate the point.

The question whether a body otherwise desirable can be presented in a form suitable for use may still demand an affirmative answer before the official portal is opened to it. This consideration may involve the separation of active principles from antagonistic or undesirable principles associated with them in vegetable remedies, but it especially involves the retention of the valuable active properties of a remedy in such a form as can be utilised by the practitioner.

Ozone is a body to which considerable value is attributed in treatment of certain cases : but if it is to be of service, a standardised preparation, which would retain its activity would be desirable, for the employment of a gas of unknown strength would probably in its results he either useless or positively harmful. Possibly as a substitute a solution of the closely-related peroxide of hydrogen might be employed.

To recognise nitrous-oxide gas or oxygen, except in such a condensed form as would admit of their development in large volume from small bulks, would be to deny them to the practitioner, and the same may be said of some of the energetic local anæsthetics, which cannot be made the objects of an ordinary dispensary process.

These bodies are all prepared extra-pharmacopœially in useful forms, and, though some of them may be held to have a sufficiently important action to recommend them, the question of their admittance to the British Pharmacopoia may have to turn on the possibility of rerognising them in such a form as will admit of every-day employment in practice.

THE first annual report of the directors of the David Lewis Trust states that the Manchester Committee has allotted out of the capital sum a grant not exceeding $£ 70,000$ towards hospitals to be erected in Gloucester Street and Stanley Grove, and that the Liverpool Committee have allocated a

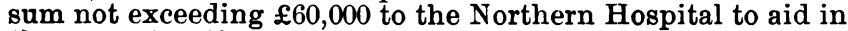
the reconstruction.

\section{THE ANTITOXIN TREATMENT OF DIPHTHERIA.}

\author{
THE STORAGE OF ANTITOXIN.
}

Professor Thomas R. Fraser (University of Edinburgh)' writes :

It seems to me that much unnecessary trouble is being taken in the storage and distribution of diphtheria antitoxin. I refer to the elaborate precautions which are required so long as it continues to retain its liquid form. I would suggest that in future the liquid antitoxin should, as soon as it has been obtained, be evaporated in vacuo over sulphuric acid, and stored and distributed in the form of a dry powder, whose exact quantitative relationship to the liquid antitoxin or to the toxin itself could easily be ascertained and stated. There can be no doubt that in this dry form diphtheria and all other antitoxins will retain almost indefinitely their original effects. Were this plan adopted it would also be possible considerably to reduce the bulk of fluid injected under the skin.

XLVIII.-Mr. E. F. FlynN, L.R.C.S., L.R.C.P. (Leathwaite Road. Clapham Common), writes as follows:

E. R., aged 8, was in her usual health until the afternoon of January 15th, 1895, when she felt languid and ill. The temperature was $102^{\circ}$, the pulse 120 , and slight membranous patches were present on both tonsils. At 8 P.M. that evening the temperature was $104^{\circ}$, and the pulse 140 ; both tonsils were very much inflamed and covered with a greyish exudation, and the breath had a very foul smell ; the cervical glands were enlarged and very painful, and there was intense pain in the ears. The condition was much the same at 12.30 A.M., but the child was delirious. At 5 A.M. no improvement had taken place. At 10 A.M. the temperature was $102^{\circ}$, and the local condition was much as before. At 3 P.M. I injected 20 c.cm. of antidiphtherial serum, prepared by Messrs. Burroughs, Wellcome, and Co., into the loose tissue at the back of the scapula. At 8 P.M. the temperature was $103^{\circ}$, pulse 120 , but the throat condition had improved. A spray of lactic acid and papain was used.

On January 17 th, at 10 A.M.. the temperature was $100^{\circ}$, and the general and local condition was much improved. From this date she quickly improved, and made an unusually rapid recovery. About eight days after injection she had slight urticaria, and complained of pains in the limbs.

On December 17th, 1894, F. R., aged 6 years, brother of the above patient, died in 36 hours from diphtheria, not treated with antitoxin.

On December 20th Mrs. R., the mother, contracted diphtheria from kissing her child, but in a milder form, and recovered after being treated locally and constitutionally with tincture of the perchloride of iron.

\section{REPORTS OF CASES TREATED BY DR. KLEIN'S. ANTITOXIN.}

The Gengral Infirmary, Chester.

XLIX.-Reported by Richard Hamilton, M.B.Lond., HouseSurgeon.

CASE I.-M. S., aged 4, admitted December 10th, 1894. Membrane was present on each tonsil, the cervical glands were enlarged, and albumen was present in the urine. Temperature $100^{\circ}$, respirations 28 , and pulse 120 per minute. There was no rash; tongue very furred. At 5 P.M. $80 \mathrm{~m}$ of antitoxin were injected into the back. Temperature $98.6^{\circ}$ pulse 128 , respirations 24 .

December 11th. Neck was more swollen, throat cleaner; temperature normal at 4 A.M.

December 12th. Patient was better. Respirations 24, pulse 116, temperature $98^{\circ}$. The quantity of albumen had increased.

December 13th. The throat was free from membrane. Tem-perature $97.6^{\circ}$, pulse 120 , respirations 24 . Albumen $\frac{1}{5} \mathrm{by}^{\circ}$ volume.

December 15th. Albumen was $\frac{5}{6}$ by volume. Otherwise the 